\title{
Impact of Secured Prescription Implementation for Zolpidem on Hypnotics Use in France: A Time-Series Analysis on National Data
}

\author{
Nicolas Rousselot, MD, MSc1 \\ Antoine Pariente, $\mathrm{MD}, \mathrm{PbD}^{2,3}$ \\ Yobann Mansiaux, $\mathrm{PbD}^{2}$ \\ Caroline Victorri-Vigneau, \\ PharmD, $\mathrm{PbD}^{4}$
}

'Department of General Practice, University of Bordeaux, Bordeaux, France

${ }^{2}$ Inserm U1219, Bordeaux Population Health Research Center, team Pharmacoepidemiology, Bordeaux, France

${ }^{3} \mathrm{CHU}$ de Bordeaux, Pole de Santé Publique, Service de Pharmacologie Médicale, Centre de Pharmacovigilance de Bordeaux, Bordeaux, France

${ }^{4}$ Department of Clinical Pharmacology, University Hospital of Nantes, Nantes, France

Conflicts of interest: authors report none.

\section{CORRESPONDING AUTHOR}

Nicolas Rousselot, MD, MSc Département de Médecine Générale Université de Bordeaux, Case 148 146 rue Léo Saignat, 33076 Bordeaux cedex France nicolas.rousselot@u-bordeaux.fr

\begin{abstract}
We evaluated the impact of the implementation of a requirement that zolpidem prescriptions be obtained via secured forms (April 2017) on zolpidem and other hypnotics use in France. We conducted a time-series analysis on data from the French national health care system, from January 1, 2015 to January 3, 2018, for all reimbursed hypnotics. An important and immediate decrease in zolpidem use $(-161,873$ defined daily doses [DDD]/month; $-215,425$ to $-108,323)$ was evidenced, with a concomitant raise in zopiclone use $(+64,871 ;+26,925$ to $+102,817)$. These findings suggest that the change in zolpidem prescribing policies was effective, but has resulted in a shift from zolpidem to zopiclone. Further interventions are needed to decrease hypnotics' overuse in France.
\end{abstract}

Ann Fam Med 2020;18:345-348. https://doi.org/10.1370/afm.2556.

\section{INTRODUCTION}

$\mathrm{B}$ enzodiazepines and non-benzodiazepines hypnotics are used widely worldwide. ${ }^{1}$ Along with opioids, these drugs are monitored particularly for their potential for misuse, abuse, dependency, and serious adverse effects. Over the years, the successive interventions and guidelines aiming to limit their use have shown limited impact. ${ }^{2}$ During recent years, zolpidem was the most frequently used hypnotic in France and one of the drugs most involved in diversion or falsification of prescriptions. ${ }^{2-4}$

On April 10, 2017, the French Health Authorities (ANSM) implemented new prescription rules for zolpidem. These new rules made it mandatory to use secured prescription forms for zolpidem, as was and is still required for medical narcotics. On these tamper-resistant forms, prescribers have to write out entirely in letters the dosage, therapeutic units per dose, and number of doses. The aim of this type of form is to limit abuse, counterfeiting, and diversion possibilities. ${ }^{3}$ Other hypnotic drugs, however, were not required to be prescribed using secured prescription forms.

Our objective was to evaluate the impact of this intervention on zolpidem and other hypnotics use in France.

\section{METHODS}

We used Medic'AM opendata provided by the French national health care system (covering about 67 million people). ${ }^{5}$ This dataset contains nationwide quantitative information on all drug reimbursements performed monthly in France. From this data, from January 2015 to March 2018, we estimated the monthly number of reimbursed defined daily doses (DDDs, the assumed average maintenance dose per day for a drug used for its main indication in adults) for all oral drugs marketed with a hypnotic indication in France. This was latter converted to equivalent-zolpidem DDDs for all drugs but alimemazine. ${ }^{6}$ 


\section{Table 1. Impact of Secured Prescription Implementation for Zolpidem on Hypnotics Use in France} (in Number of Reimbursed Defined Daily Doses per Month; Unit is 1,000 DDDs)

\begin{tabular}{|c|c|c|c|}
\hline & $\begin{array}{c}\text { Prior Trend }(1 / 15-3 / 17) \\
\text { No. }(95 \% \mathrm{CI})\end{array}$ & $\begin{array}{l}\text { Level Change } \\
\text { (Intervention Time: 4/17) } \\
\text { No. }(95 \% \mathrm{Cl})\end{array}$ & $\begin{array}{c}\text { Trend Change } \\
\text { (5/17-3/18 vs } 1 / 15-3 / 17) \\
\text { No. }(95 \% \mathrm{Cl})\end{array}$ \\
\hline Zolpidem & $-2.95(-4.79$ to -1.12$)$ & $-161.87(-215.42$ to -108.32$)$ & $-14.39(-20.87$ to -7.91$)$ \\
\hline Zopiclone & $-0.76(-2.06$ to 0.54$)$ & 64.87 (26.92 to 102.82$)$ & $6.62(2.02$ to 11.21$)$ \\
\hline Estazolam & $-0.06(-0.11$ to -0.01$)$ & $-1.44(-2.88$ to 0.00$)$ & $-0.10(-0.27$ to 0.07$)$ \\
\hline Nitrazepam & $-0.12(-0.23$ to -0.01$)$ & 3.17 (0.01 to 6.32$)$ & $-0.41(-0.80$ to -0.03$)$ \\
\hline Loprazolam & $-0.28(-0.47$ to -0.08$)$ & $4.76(-0.85$ to 10.36$)$ & $0.31(-0.37$ to 0.98$)$ \\
\hline Lormetazepam & $0.11(-0.74$ to 0.96$)$ & $17.69(-7.18$ to 42.55$)$ & $2.42(-0.59$ to 5.43$)$ \\
\hline Alimémazine & $0.05(-0.32$ to 0.43$)$ & $4.18(-6.70$ to 15.06$)$ & $-1.16(-2.47$ to 0.16$)$ \\
\hline $\begin{array}{l}\text { Zolpidem + zopiclone (equiv- } \\
\text { alent zolpidem) }\end{array}$ & $-3.71(-6.16$ to -1.27$)$ & $-97.00(-168.40$ to -25.61$)$ & $-7.77(-16.42$ to 0.87$)$ \\
\hline $\begin{array}{l}\text { All except alimémazine } \\
\text { (equivalent zolpidem) }\end{array}$ & $-4.31(-8.17$ to -0.45$)$ & $-69.66(-182.32$ to 43.00$)$ & $-4.95(-18.59$ to 8.69$)$ \\
\hline
\end{tabular}

We first deseasonalized the obtained time-series data using the moving average method. We analyzed them afterward using standard segmented regression models to compare the observed trends in individual hypnotic reimbursement before and after April 2017. Sensitivity analyses were performed, considering May and June 2017 as the interruption dates to account for potential lag in application of the intervention. All analyses were conducted using R, version 3.4.3 (R Project for Statistical Computing), and the forecast, nlme, and TSA packages.

No ethic committee approval is required for use of these publicly accessible anonymized aggregated open data.

\section{RESULTS}

Over the January 2015-March 2017 time period, reimbursements for zolpidem varied around 700,000 DDDs/month, with a significant decreasing trend estimated at $-2,954 \mathrm{DDDs} /$ month $(95 \% \mathrm{CI},-4,791$ to $-1,117)$. The timing of the intervention in April 2017 was accompanied by a significant level decrease in the use of zolpidem of $-161,873$ DDDs/month $(-215,425$ to -108,323). Over the May 2017-March 2018 following period, the series presented with an acceleration in decreasing trend estimated at $-14,392$ DDDs/month $(-20,874 \text { to }-7,910)_{\text {i }}$ in March 2018, zolpidem reimbursements appeared almost halved compared to January 2015 (Table 1, Figure 1).

Opposite changes were observed for zopiclone (around 500,000 DDDs/month, stable in the preintervention period) both in terms of level $\left(+64,871_{\text {; }}\right.$ $+26,925$ to $+102,817)$ and trend $(+6,618 ;+2,025$ to $+11,211$ ). In March 2018, zopiclone reimbursements almost reached 616,000 DDDs.

Taken together, the use of these 2 drugs was associated with a statistically significant decrease in level; the decrease in trend did not conversely reach statistical significance.

Changes for other hypnotics appeared minor (level decrease for estazolam, level increase and trend decrease for nitrazepam, Table 1).

Sensitivity analyses found the most important delivery changes occurred in April 2017, the exact month of the intervention, rather than in May or June.

\section{DISCUSSION}

In France, the implementation of the prescription of zolpidem using secured forms led to an important and immediate decrease in zolpidem use that was partially compensated for by a raise in zopiclone use. To our knowledge, no other event could explain observed changes during the study period. This analysis demonstrated the intervention resulted in limiting zolpidem use, although that was not the official aim of the rule change. ${ }^{3}$ It also suggests that, although abuse and diversion were described as being more problematic with zolpidem in France, ${ }^{2,3,7,8}$ this change in prescribing policies could just have shifted part of the problem to zopiclone. Consequently, the emergence of the use of alternative drugs with similar diversion potential - as already observed in the past after the implementation of other benzodiazepine prescribing restrictions- has to be monitored. ${ }^{4}$

Our study was based on aggregated ambulatory reimbursement data. These data are representative of the French population and contain information close to that of actual consumption. A limitation of this study is that aggregated data do not allow for performing investigations at the individual level. Consequently, they do not allow for identifying and quantifying the number of consumers and misusers to describe the switches performed in patients, or for determining if 
Figure 1. Impact of zolpidem secured prescription implementation on hypnotics ambulatory delivery in France (in monthly defined daily dose).

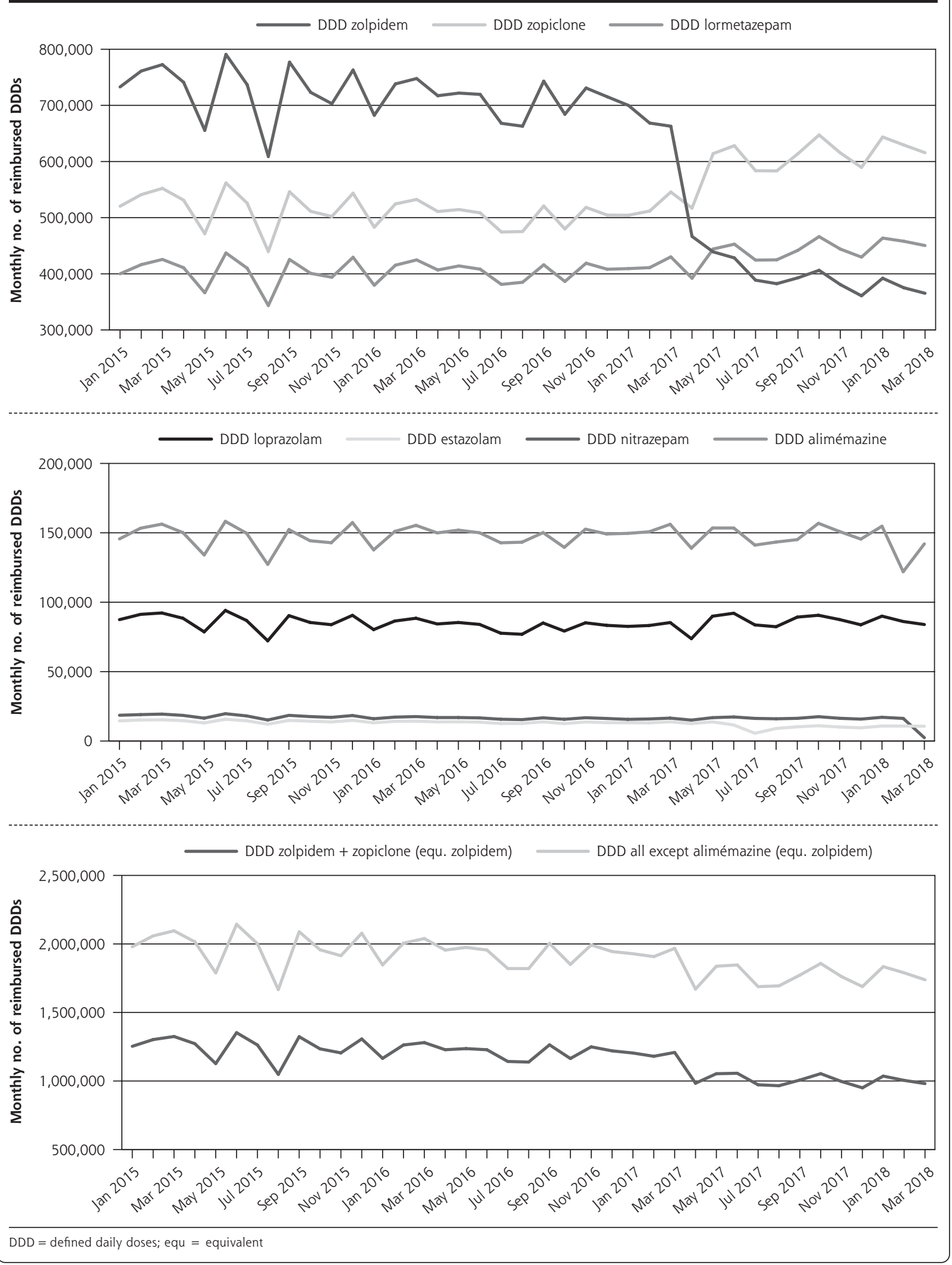


the observed reduction in total prescriptions came from fraudulent use, inappropriate prescribing, and/or a switch made by prescribers finding it easier to prescribe alternatives, such as zopiclone. ${ }^{9}$ Complementary studies using data sources providing individual-level data are needed. ${ }^{10}$

Even if this intervention appeared effective for reducing zolpidem use, others will be needed to contribute to the decrease of hypnotics' overuse in France. Because our study was centered on zolpidem, the overall impact of this intervention on hypnotic and anxiolytics use remains to be explored; even our data suggest that little net gain could have been obtained when considering global hypnotics use evolution. This might imply that the measure should not be generalized to all hypnotics. Doing so would result in increasing prescription burden for physicians ${ }^{9}$ and might result in shifts towards other misused prescribed drugs.

To read or post commentaries in response to this article, see it online at https://www.AnnFamMed.org/content/18/4/345.

Submitted August 19, 2019; submitted, revised, November 30, 2019; accepted December 9, 2019.

Key words: zolpidem; hypnotics and sedatives; health policy; drug prescriptions; ambulatory care; interrupted time-series analysis

Author contributions: Study concept and design: N.R., A.P., C.V.V. Acquisition: N.R. Analysis, or interpretation of data: All authors. Drafting of the manuscript: N.R. Critical revision of the manuscript for important intellectual content: All authors. Statistical analysis: Y.M. Study supervision: A.P., C.V.V.

\section{References}

1. Lembke A, Papac J, Humphreys K. Our other prescription drug problem. N Engl J Med. 2018;378(8):693-695.
2. Bénard-Laribière $A$, Noize $P$, Pambrun $E$, Bazin F, Verdoux $H$, Tournier $\mathrm{M}$, et al. Comorbidities and concurrent medications increasing the risk of adverse drug reactions: prevalence in French benzodiazepine users. Eur J Clin Pharmacol. 2016;72(7):869-876.

3. Agence Nationale de Sécurité du Médicament et des produits de santé (FR). Prescription obligatoire du zolpidem sur ordonnance sécurisée - Point d'Information [Mandatory prescription of zolpidem on secure prescription - Information Point]. https://ansm. sante.fr/S-informer/Points-d-information-Points-d-information/ Prescription-obligatoire-du-zolpidem-sur-ordonnance-securiseePoint-d-Information. Published Jan 1, 2011. Accessed Oct 14, 2011.

4. Jouanjus E, Guernec G, Lapeyre-Mestre M; French Addictovigilance Network. Medical prescriptions falsified by the patients: a 12-year national monitoring to assess prescription drug diversion. Fundam Clin Pharmacol. 2018;32(3):306-322.

5. Medic'AM - Données mensuelles et annuelles sur les médicaments remboursés par l'Assurance Maladie. https://www.ameli.fr/l-assurancemaladie/statistiques-et-publications/donnees-statistiques/medicament/ medic-am/medic-am-2008-2013.php. Accessed Jun 16, 2018.

6. Benzo.org.uk. Benzodiazepine equivalence table. https://www.benzo. org.uk/bzequiv.htm. Published Apr 2007. Accessed Jun 17, 2018.

7. Victorri-Vigneau C, Feuillet F, Wainstein L, et al. Pharmacoepidemiological characterisation of zolpidem and zopiclone usage. Eur J Clin Pharmacol. 2013;69(11):1965-1972.

8. Rousselet M, Feuillet F, Gerardin M, Jolliet P, Hardouin J-B, VictorriVigneau $C$. The French addictovigilance network clinical assessment: Z-drugs, true false twins. Expert Opin Drug Saf. 2017;16(9): 1063-1069.

9. Daveluy A, Sauvaget L, Bastien A, et al. Tamper-resistant prescription forms for narcotics in France: should we generalize them? Fundam Clin Pharmacol. 2018;32(5):571-577.

10. Gérardin $M$, Rousselet $M$, Caillet $P$, Grall-Bronnec $M$, Loué $P$, Jolliet $P$, et al. French national health insurance database analysis and field study focusing on the impact of secure prescription pads on zolpidem consumption and sedative drug misuse: ZORRO study protocol. BMJ Open. 2019;9(6):e027443. 